\title{
Coulisses
}

Revue de théâtre

14 | Printemps 1996

Varia

\section{Notes de lecture : Jean Verdeil, Le Travail du metteur en scène}

\section{Christian Pratoussy}

\section{(2) OpenEdition}

1 Journals

Édition électronique

URL : http://journals.openedition.org/coulisses/4905

DOI : $10.4000 /$ coulisses.4905

ISSN : 2546-9460

\section{Éditeur}

Presses universitaires de Franche-Comté

\section{Édition imprimée}

Date de publication : 1 mai 1996

Pagination : 84

ISSN : 1150-594X

\section{Référence électronique}

Christian Pratoussy, " Notes de lecture : Jean Verdeil, Le Travail du metteur en scène », Coulisses [En ligne], 14 | Printemps 1996, mis en ligne le 20 mars 2019, consulté le 30 octobre 2019. URL : http:// journals.openedition.org/coulisses/4905; DOI : 10.4000/coulisses.4905

Ce document a été généré automatiquement le 30 octobre 2019.

Coulisses 


\title{
Notes de lecture : Jean Verdeil, Le Travail du metteur en scène
}

\author{
Christian Pratoussy
}

\section{RÉFÉRENCE}

Jean Verdeil, Le Travail du metteur en scène, Lyon, Aléas, 1995, 168 p.

1 Le sous-titre de l'ouvrage est : Un exemple, Lyon. C'est, en effet, la capitale des Gaules, et pour le moins la deuxième ville française du théâtre (comme certains le prétendent), que Jean Verdeil, professeur d'Etudes théâtrales à l'Université Lumière-Lyon 2, a choisi pour aller à la recherche du « comment ça marche». Travail de théoricien, l'ouvrage est aussi totalement inscrit dans la réalité, lyonnaise en l'occurrence. Tout ce qui compte comme hommes et femmes de théâtre dans cette ville a été convoqué. Par ordre alphabétique: Carlucci, Chavassieux, Clément, Faure, Françon, Lavaudant, Maimone, Martinelli, Meyssat, Yendt, Znorko. Il n'y manquerait qu'un Planchon, mais on l'a déjà entendu par ailleurs, et un Lucet, le directeur de ce qui est probablement aujourd'hui la meilleure réussite, au moins sur le plan économique, à savoir le Théâtre des Célestins. Ainsi, si le travail du metteur en scène a un indéniable intérêt local, il offre aussi l'incontestable originalité de présenter, avec des hypothèses probablement représentatives, la recherche du « régisseur », pour reprendre le mot favori de Vilar.

2 Jean Verdeil a procédé par thèmes avec ses témoins. Entre autres, il leur a posé les questions de l'identité du metteur en scène, du choix des textes, de la distribution, de la formation des comédiens, des rapports du comédien avec le personnage, etc. En introduction à ce panorama, où il ne manquerait éventuellement que la question du public, l'auteur expose son parti pris méthodologique : « Il y avait deux manières bien différentes de concevoir cet ouvrage : faire une analyse théorique qui n'aurait reflété qu'un seul point de vue ou au contraire, partir des méthodes de travail de chacun des metteurs en scène interrogés, montrer les différences dans les pratiques, et essayer de voir si des présupposés théoriques se trouvaient à l'origine des choix. Dans un cas, je 
proposais une démarche préalable et j'essayais de la faire coïncider avec des pratiques, dans l'autre, à partir de l'analyse des pratiques, j'essayais de délimiter des champs théoriques où s'inscrivaient les différences et les contradictions. C'est la méthode que j'ai choisie».

3 Jean Verdeil ne s'étendra pas sur cette méthodologie qui a le mérite d'être claire, même si on devine les questions qu'elle pose, notamment l'endroit du statut de la «théorie » au théâtre et du statut de la théorie en « sciences humaines ». De fait, l'ouvrage, en plus de l'aspect monographique qu'il présente, sachant qu'il est bien loin de n'être destiné qu'à un public d'universitaires, acquiert aussi le statut de modèle théorique d'analyse à destination du chercheur.

4 Tout au long du livre, nous retrouvons pour chacun des thèmes d'investigation la présentation des témoignages suivie d'une synthèse théorique qui, nous pouvons l'imaginer, ne fut certainement pas la partie la plus aisée du travail tant les sources d'inspiration des metteurs en scène considérés sont différentes et font appel à des notions parfois bien lointaines : par exemple un Philippe Clément, directeur du Théâtre de l'Iris à Villeurbanne, est assez « orientaliste ».

5 Grâce soit rendue, à ce propos, à l'auteur d'avoir adjoint un glossaire, pour éclairer la lanterne du lecteur néophyte, où l'on trouve aussi bien la biographie de Craig, de Stanislavski, qu'une définition de "didascalies", de "Taï Chi Chuan» ou autre «Travail à la table ». Pour rester dans le domaine des annexes, nous pouvons regretter par contre l'absence d'une bibliographie, non tant dans son acception universitaire, qu'en tant que compléments de lecture recommandée par les metteurs en scène rencontrés.

6 Il n'en demeure pas moins que Jean Verdeil nous livre là un exemplaire travail dans son champ théorique nouveau : l'ethno-esthétique, dont on serait en droit d'attendre une suite tant certaines questions posées sont stimulantes. Un exemple suffit à le prouver :

L'idée d'une école de théâtre propre à Lyon permettrait peut-être d'aborder une question jamais étudiée en profondeur, toujours esquivée : la formation au jeu dramatique relève-t-elle d'un travail de comédiens, ou d'un travail plus spécifique qu'un comédien et formateur aguerri comme Miguel Demuynck appelle un dramaticien? 